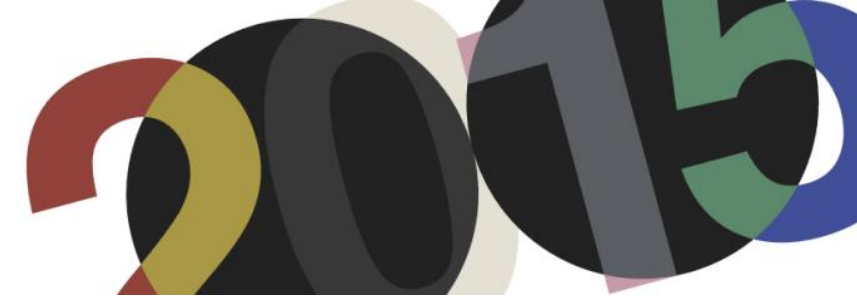

DOI: http://dx.doi.org/10.4995/LC2015.2015.976

\title{
FLC 4932. Lo inesperado en la obra de Le Corbusier. Consideraciones en torno al origen de la promenade
}

\author{
R. Miralles Jori \\ Escuela Técnica Superior de Arquitectura de la Universitat Rovira i Virgili
}

\begin{abstract}
Resumen: Entender la evolución de la idea de la promenade en la crítica corbuseriana. Cómo la idea ha ido pasando de la idea del movimiento al pintoresquismo, a lo cinematográfico y finalmente a la idea de montaje. Leyendo Le Corbusier entender que lo mas relevante de la promenade es la idea de lo inesperado para el espectador. Entender de dónde viene esta idea de lo inesperado a través de la formación de Le Corbusier y, sobretodo, a partir de su formación en la crítica del S.XIX. Especialmente importante para entender la idea de lo inesperado es el libro de Mornings in Florence de Ruskin, en especial su descripción de la capilla de los españoles. Esta capilla también será objeto de estudio por Le Corbusier y, en ella, reconoce la importancia de lo inesperado en arquitectura.
\end{abstract}

Abstract: The first objective of this paper is to understand the evolution of the idea of promenade in Le Corbusier's critic. The paper follows how the idea has changed from the movement to the picturesque, to the cinematographic and finally to the idea of montage. The second objective is to understand that the idea of the unexpected for the spectator is key for the promenade. Then we try to understand where does the idea of the unexpected come in Le Corbusier's formation with special interest in his formation in the nineteenth century critics. And how important to understand the idea of the unexpected is Ruskin's Mornings in Florence, specially his description of the Spanish Chapel. This chapel will be case study for Le Corbusier and in his study he recognises the importance of the unexpected in architecture.

Palabras clave: Promenade, Espacio inesperado, Formación de Le Corbusier, Viajes de Le Corbusier, Capilla de los españoles.

Keywords: Promenade, Unexpected space, Le Corbusier formation, Le Corbusier Travels, Spanish Chapel.

\section{1.}

Le Corbusier forjó muchos conceptos arquitectónicos que han hecho fortuna: cubierta jardín, planta libre, promenade, etc. Este último término lo usamos en francés. No traducimos promenade -los anglosajones tampoco- porque algo se pierde en la traducción, cuestión de matiz. No, cuando hablamos de promenade no hablamos sólo de un paseo. Una palabra francesa en el vocabulario que manejamos para hablar de Le Corbusier sirve para entender que la promenade no es sólo un paseo. Le Corbusier para introducir la cuestión de matiz alargaba el término y le añadía el adjetivo architecturale y lo escribía siempre en versales. Cuál es ese matiz que introducimos al hablar de promenade o de promenade architecturale y saber su origen es el objeto de estudio de este artículo.

La idea de promenade architecturale ha tenido muy buena fortuna crítica y goza de muchas definiciones. Sin intención de ser exhaustivos, haremos un breve repaso por las que creo más significativas. En un monográfico reciente sobre el tema, Flora Samuel, empieza dando una definición: "Taken to a basic level the promenade refers, of course, to the experience of walking through a building." La traducción literal; pero Samuel no habría hecho un monográfico sobre el tema si no añadiera un matiz: "Taken at a deeper level, like most things Corbusian, it refers to the complex web of ideas that underpins his work, most specifically his belief in 
architecture as a form of initiation "'. El matiz es complejo. Entendemos que la arquitectura es una disciplina hermética en la que podemos iniciarnos y, según Samuel, Le Corbusier considera que la promenade es la vía. Al leer la definición y el monográfico que le sigue, uno piensa que la autora se refiere más a la fortuna crítica de la palabra que al significado que tenía para Le Corbusier. Esta definición no nos permite entender porqué escribimos promenade en versales o la acompañamos de architecturale pero nos deja con la idea de movimiento.

Tradicionalmente la idea de movimiento se ha asociado a este concepto corbuseriano por el significado propio del término promenade. El profesor Cohen al hablar del paisaje, lo ha explicado como la visión en movimiento ${ }^{2}$. Cohen remite al texto 'vision in motion' de Moholy-Nagy para hacerlo comprensible; aunque, como señala el propio Cohen, sea posterior a la aparición de las 'estrategias de percepción en movimiento' en Le Corbusier. El libro de Moholy-Nagy ${ }^{3}$ empieza definiendo la visión en movimiento. Una definición extensa, de una página, en la que nos hace ver que la visión en movimiento es a la vez percepción simultánea de varios fenómenos que hacen un todo; un nuevo modo de comprender la visión a través de un mismo espacio-tiempo; ver mientras uno se mueve pero también ver los objetos moviéndose - en realidad o a través del arte; también se entiende la visión en movimiento como la proyección dinámica de las posibilidades visionarias. Moholy-Naghy mezcla muchos conceptos que no sé si estaban en la cabeza de Le Corbusier al tratar de acotar el significado de la promenade. En cualquier caso no nos sirve para introducir el matiz que buscábamos porqué es un concepto demasiado amplio.

Cohen, y la tradición a la que hacíamos referencia, lo que hacen es asociar el movimiento no a algo general sino al sujeto que se mueve por dentro de la arquitectura. Esa tradición lo que hace es asociar el nombre de Le Corbusier al del pintoresquismo. Así lo estableció Etlin: "In Le Corbusier's mind, then, the lessons of sequential spaces and balanced picturesque composition taught by Sitte and Choisy and confirmed by the experience of a trip to the East came together to establish the primacy of the architectural promenade while offering guidalines for its realization ${ }^{4}$." La versión de Etlin es en la que el espectador compone unas imágenes que generan composiciones balanceadas, la suma de ellas es la promenade. La duda que a uno le puede venir leyendo a Etlin es en que punto debe el espectador componer la imagen balanceada o si el punto no importa ya que todas las visiones son balanceadas. Esta cuestión la ha tratado de resolver MacArthur quien, en un libro sobre el pintoresquismo dedica un capítulo a Le Corbusier y en un pasaje explica: "As well as being picturesque, we can also understand the promenade as being cinematrographic -the two concepts are not unrelated. In retrospect, we can see the eighteenth-century picturesque as pictoriality with movement added. (...) in the strong cases of the picturesque garden or Le Corbusier's architectural promenade, tries to give space sequence, direction and even narrative ${ }^{5}$.

La visión de MacArthur es la de alguien que teóricamente ha unido el pintoresquismo al movimiento y eso le ha llevado a lo cinematográfico, pero no resuelve el problema que se nos planteaba al leer a Etlin.

\footnotetext{
${ }^{1}$ Samuel, Flora, Le Corbusier and the Architectural Promenade, Birkhäuser, Zurich, 2010

${ }^{2}$ Cohen, Jean-Louis, Le Corbusier: An Atlas of Modern Landscapes, Museum of Modern Art, New York 2013, p.36 - The idea of 'vision in motion', made popular in 1947 by Lazlo Moholy-Nagy, transposes the dynamic caracter of the observational strategies deployed by Le Corbusier. The major breaks that mark his thoughts on city and landscape can be traced back to his discovery of new modes of travel, each one radically altering his perception and method of notation.

${ }^{3}$ Moholy-Nagy, László, Vision in Motion, Theobald, Chicago, 1947, p.12

${ }^{4}$ Etlin, Richard A., Frank Lloyd Wright and Le Corbusier. The romantic legacy, Manchester University Press, Manchester, 1994, p.115

5 John MacArthur, The Picturesque, Architecture, Disgust and other Irregularities. Routledge (Taylor and Francis group) London, 2007, p.164.
} 
Fue Tim Benton quien probó, empíricamente -cámara en mano-, de filmar la promenade y concluyó: "que tomar la promenade literalmente, como el punto de vista continuamente cambiante de una persona que recorre un edificio, significa no comprender su verdadero sentido $6 "$. Benton explica que tratando de filmar la promenade en la Villa Savoye, se dieron cuenta de que "una promenade se puede escenificar y rodar, pero las imágenes para ilustrarla deben apartarse del punto de vista del ojo cinético de la persona que se mueve por el edificio. El paseo, en un sentido importante, es virtual más que real; hay que usar la imaginación espacial a medida que uno se mueve por el edificio en lugar del foco monocular de una cámara ${ }^{7}$ ". Esta teoría de que el sentido de la promenade es virtual explica que es el espectador el que tiene que construir en su cabeza las relaciones al ir paseando; como dice Colomina: "That is, the house is not simply constructed as a material object from which certain views become posible. The house is no more than a series of views choreographed by the visitor, the way a filmmaker effects the montage of a film ${ }^{8}$." El tema de la construcción o el montaje para dar un sentido a la promenade es el que desarrollará Martínez de Guereñu en su artículo sobre el montaje en Le Corbusier. Martínez de Guereñu sostiene que los encuadres acaban siendo pares de opuestos -otra vez pintorescos- que los habitantes “debían 'montar' en su mente, producían un juego de relaciones que dotaban a las obras arquitectónicas de una cualidad estética que trascendía las meras construcciones funcionalistas modernas. Porque tal y como demostraron Eisenstein y Le Corbusier insistentemente, la arquitectura también debía permitir la participación del hombre" 9 . Una explicación práctica de esta teoría es el libro de Quetglas sobre la Villa Savoya ${ }^{10}$.

La explicación de lo cinematográfico unido a lo pintoresco no nos resuelve la pregunta de si hay imágenes que son las escogidas o porqué escogemos unas y no otras. El lenguaje cinematográfico cuando quiere remarcar una imagen usa el recurso del tiempo -u otros- para hacernos entender que esa es la importante. ¿Cual es, en el lenguaje arquitectónico, el recurso para hacernos entender, al espectador, cual es la imagen importante?

Entendemos, pues, que la promenade es una sucesión de imágenes que se componen en la mente del espectador al ir transitando por la pieza arquitectónica. Vamos acotando el matiz. Ahora debemos saber qué imágenes escoger y cómo.

\section{2.}

Leer lo que se dice de alguien sirve para entender cómo lo han entendido ellos, pero si queremos saber que es la promenade es obligatorio ir a la fuente primaria.

\footnotetext{
${ }^{6}$ Benton, Tim, "Le Corbusier y la promenade architecturale”, En: Arquitectura COAM, Madrid, 1987, n.264-265.

7 op.cit., p. 45

${ }^{8}$ Colomina, Beatriz, Privacy and Publicity. Modern Architecture as Mass Media, The MIT press, 1994. p.312

${ }^{9}$ Martínez de Guereñu, Laura, "LC y el montaje", Massilia 2008, encuentro en Granada, Massilia i Associació de idees, Sant Cugat del Vallès, 2008.

${ }^{10}$ Quetglas, Josep, Les Heures Claires, Massilia, Sant Cugat del Vallès, 2008
} 


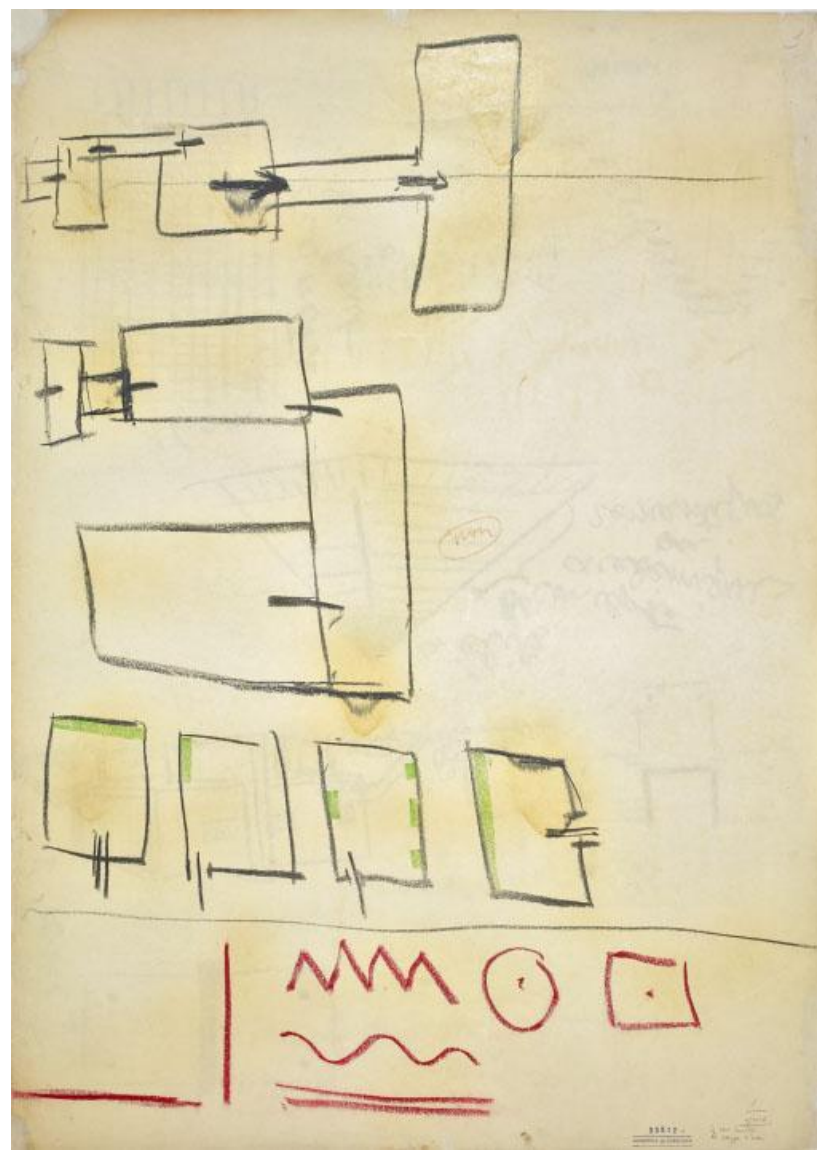

1. Pagina del libro de Precisions dónde se muestra cómo las transiciones son claves para entender el espacio.

La primera vez que Le Corbusier cita la promenade architecturale es en las primeras páginas del II volumen (1929-1934) de sus Oeuvre Complète, a propósito de la Villa Savoye: "Dans cette maison-ci, is s'agit d'un véritable promenade architecturale, offrant des aspects constamment variés, inattendus, parfois étonnants ${ }^{11}$." Es una definición poco canónica de lo que será la promenade porque no explica qué es, explica el efecto que tendrá. Le Corbusier nos anuncia lo que nos proporcionará: aspectos constantemente variados, inesperados, a veces desconcertantes. Sensaciones que se consiguen gracias al movimiento -lo que cualquier lector ya sabe al conocer el significado de promenade, sea arquitectónica o no. El movimiento es importante para poder ir enlazando espacios inesperados, variados, pero es un instrumento, lo relevante es el espacio que el espectador no espera; y la promenade enlaza estos espacios inesperados. Estas imágenes inesperadas serían las que buscábamos antes, las imágenes que al final hay que unir para tener una idea de la arquitectura, las que hay que 'montar' para entender ese edificio.

Le Corbusier hará mucho hincapié en la idea de promenade durante sus primeros años como arquitecto, pero es un concepto que hasta el Carpenter Center encontramos a menudo. Hay una descripción precisa de una promenade, aunque sin nombrarla, en una de las conferencias de Le Corbusier en Argentina:

"On entre: on reçoit un choc, première sensation. Vous voici impressionnés par telle grandeur de pièce succédant à telle autre, par telle forme de pièce succédant à telle autre. Là est l'architecture! ${ }^{12}$ ".

\footnotetext{
${ }^{11}$ Le Corbusier et Pierre Jeanneret Oeuvre Complète 1929-1934, Grisberger \& Cie, Zurich, 1934. p.29

${ }^{12}$ Le Corbusier. Précisions sur un état présent de l'architecture et de l'urbanisme, ed. Vincent, Fréal, Paris 1960, p.74
} 
En las conferencias Le Corbusier, además de hablar, dibujaba, lo sabemos porque en el libro en que están recogidas las conferencias, Precisions sur un état présent de l'architecture et de l'urbanisme, las explicaciones van acompañadas de dibujos. Cuando uno mira el dibujo que acompaña estas líneas no puede mas que imaginar la secuencia: primero, en silencio, Le Corbusier dibuja las cajas enlazadas que forman unas especies de plantas, los dos dibujos de la parte superior y luego empieza a marcar los puntos de paso cuando dice ciertas palabras clave, "entre", "succédant”, "autre”. Por si la gente lo no entiende Le Corbusier trata de ser didáctico y muestra cómo no es lo mismo entrar a una misma habitación por el centro que por un extremo o por el otro (tercer dibujo desde arriba). La sensación que interesa no parece ser la del movimiento sino la de los puntos de transición entre una situación y la siguiente; al principio, como dice Le Corbusier, se recibe un choque que provoca la primera sensación. Cada transición uno imagina que es un choque, un punto clave que queda en la memoria por insospechado. La suma de esos recuerdos son los que forjarán la promenade.

3.

Hasta aquí hemos explorado la importancia de lo inesperado en la promenade, pero al principio del texto se ha prometido que también se hablaría de dónde procedía ese gusto por lo inesperado. De su etapa de formación sabemos que:

"his taste was not characteristic of the early twentieth century but rather that of the 1860s and the Gothic Revival. John Ruskin, Owen Jones, Charles Blanc, and Hippolyte Taine were the authors he identified with i spite of having read in Henry Provensal's L'Art de demain that artists should be ahead of their time and must set standards for the future. ${ }^{13,}$

En esta preferencia por la teoría del siglo anterior encontraremos el gusto por lo inesperado en Le Corbusier.

Sabemos por Brooks, Glaseri o Daza de la importancia de los viajes de formación de Le Corbusier y por ellos sabemos también que en el primero Le Corbusier se llevó, como guía, los libros de Baedeker, Taine y Ruskin ${ }^{14}$. Aquí vamos a centrarnos en el libro de Ruskin que compró poco antes de ir de viaje, en 1907, un libro que se acababa de traducir al francés ${ }^{15}$, el “John Ruskin's Les Matins a Florence (Paris 1906; although the first English edition dates from 1875) was extraordinarily important in guiding his steps, his eyes and his mind ${ }^{16 "}$. El libro de Ruskin fue muy influyente en su formación porque según escribió en una carta a l'Epplatenier, era un libro que enseñaba a mirar ${ }^{17}$. Aprender a mirar es una expresión que explica una determinada sensibilidad, pero como detectarla. En el caso de Le Corbusier a través de cómo él nos enseña a mirar.

\footnotetext{
${ }^{13}$ H. Allen Brooks, Le Corbusier's formative years. Charles-Edouard Jeanneret at La Chaux-de-Fonds. The university of Chicago Press, Chicago 1996. p.96

${ }^{14}$ Según Brooks Cit., Glaseri, cit o Daza, Ricardo, Tras el viaje de Oriente,Fundacion Arquia, Barcelona 2015.

${ }^{15}$ Glaseri, Giuliano, Le Corbusier viaggio in oriente, Marsilio Editori, Foundation Le Corbusier, Venezia 1984., p.104 Nota 54 "L'opera di Ruskin fu acquistata da Jeanneret nell'edizione francese, appena disponibile, poco prima della sua partenza per l'Italia e letta solo durante il viaggio a susidio delle osservazioni da lui raccolte".

${ }^{16}$ Op cit. p.98.

${ }^{17}$ Le Corbusier, carta a L'Epplatenier del 19 de setiembre donde dice: "This Book [Mornings in Florence] 'teaches how to see'”. Recogido en Brooks, cit., p.102
} 

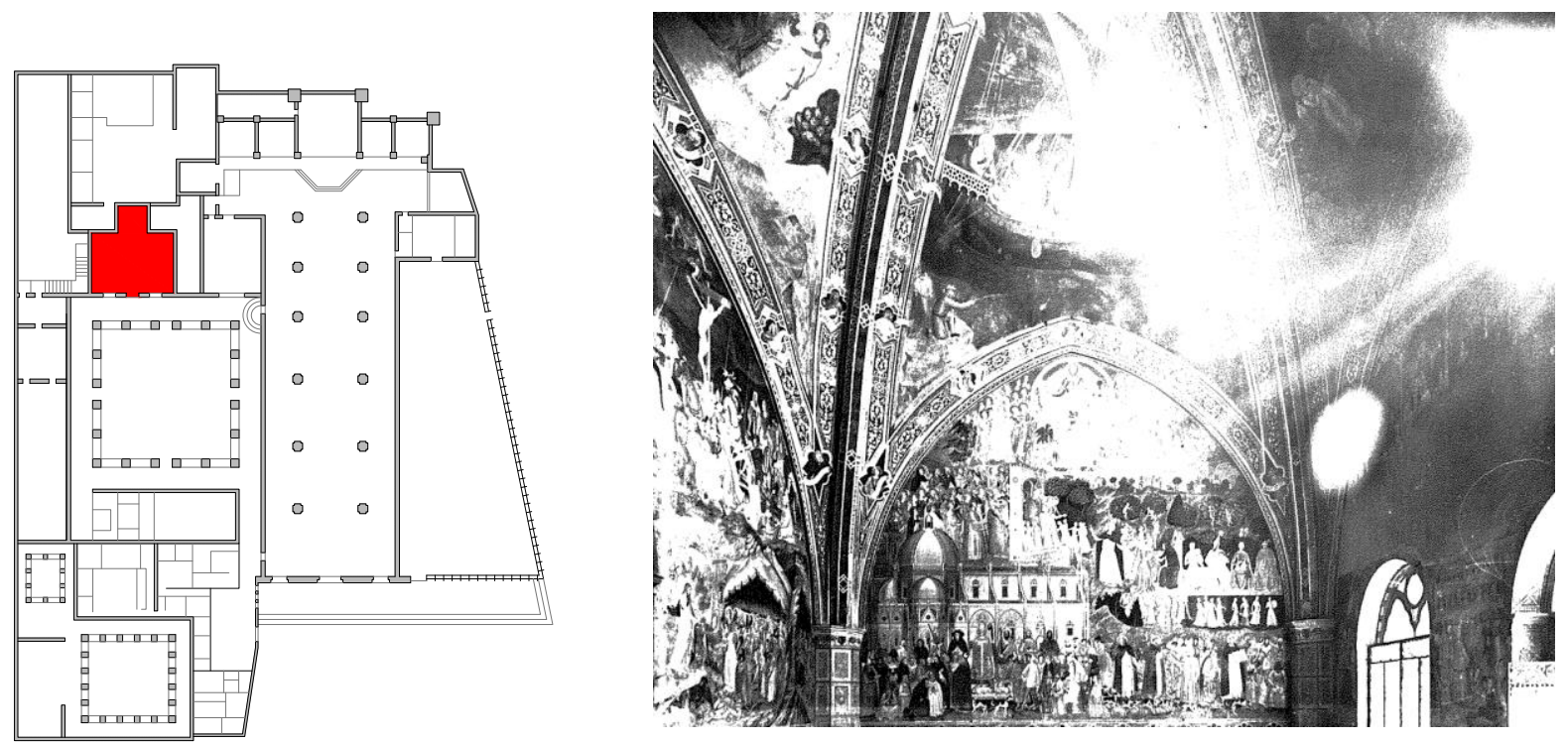

2. Planta de Santa Maria Novella, En rojo, la capilla de los españoles

3. La capilla de los españoles

Le Corbusier ha sido uno de los arquitectos con mas vocación de influencia del siglo XX, su idea de la arquitectura se puede entender tanto mirando sus edificios como leyendo sus numerosos textos. Las dos acciones, proyectar y escribir, explican la mirada de Le Corbusier. En esta ocasión nos centraremos en cómo escribe Le Corbusier ya que es más sencillo compararlo con lo que dice Ruskin que con una obra arquitectónica. Leer a Ruskin o leer a Le Corbusier significa apoyar o rechazar sus argumentos, estar a favor o en contra, no puedes no tomar partido. Ambos usan la escritura para llevarnos a su terreno, un lugar dónde hacer que su mirada sea la nuestra, un lugar dónde convencernos. Le Corbusier ha aprendido a razonar lo que se mira a través de las sentencias de Ruskin y así lo escribirá. En el libro que citábamos, Ruskin explica la capilla de los españoles en Florencia:

"no chapel, whatever, externally manifesting itself as worth entering. No walls, or gable, or dome, raised above the rest of the outbuildings -only two windows with traceries opening into the cloister; and one story of inconspicuous building above. You can't conceive there should be any effect of magnitude produced in the interior, however it has been vaulted or decorated. It may be pretty, but cannot possibly look large ${ }^{18,}$.

La descripción no se centra en la superficie o en la decoración o en el estilo arquitectónico, la descripción se encuentra en el efecto que produce la arquitectura al espectador, el efecto de magnitud que sorprende a ese espectador.

Un espectador que viene del exterior, el último estadio donde se encontraba antes de entrar al complejo de Santa María Novella es una plaza de dimensiones considerables; luego uno puede entrar bien a la iglesia o bien por una puerta lateral a la iglesia a un pasadizo que nos llevará al claustro verde. En ambos casos pasaremos de un espacio longitudinal a un claustro; nuestra visión pasará de centrarse en la linealidad y el espacio cerrado en el que estábamos -el contrario de la plaza abierta- a un centro abierto. En esta progresión, al entrar al siguiente espacio, tocaría otro lugar lineal, cerrado. Pero no encontramos eso. Encontramos algo inimaginable, algo de una magnitud insospechada, la capilla de los españoles. Dejarse llevar por ese efecto es lo que hace uno que ha aprendido a mirar con Ruskin.

\footnotetext{
${ }^{18}$ Ruskin, John, Mornings in Florence, The Mersion company, New York, 1897. p. 122.
} 


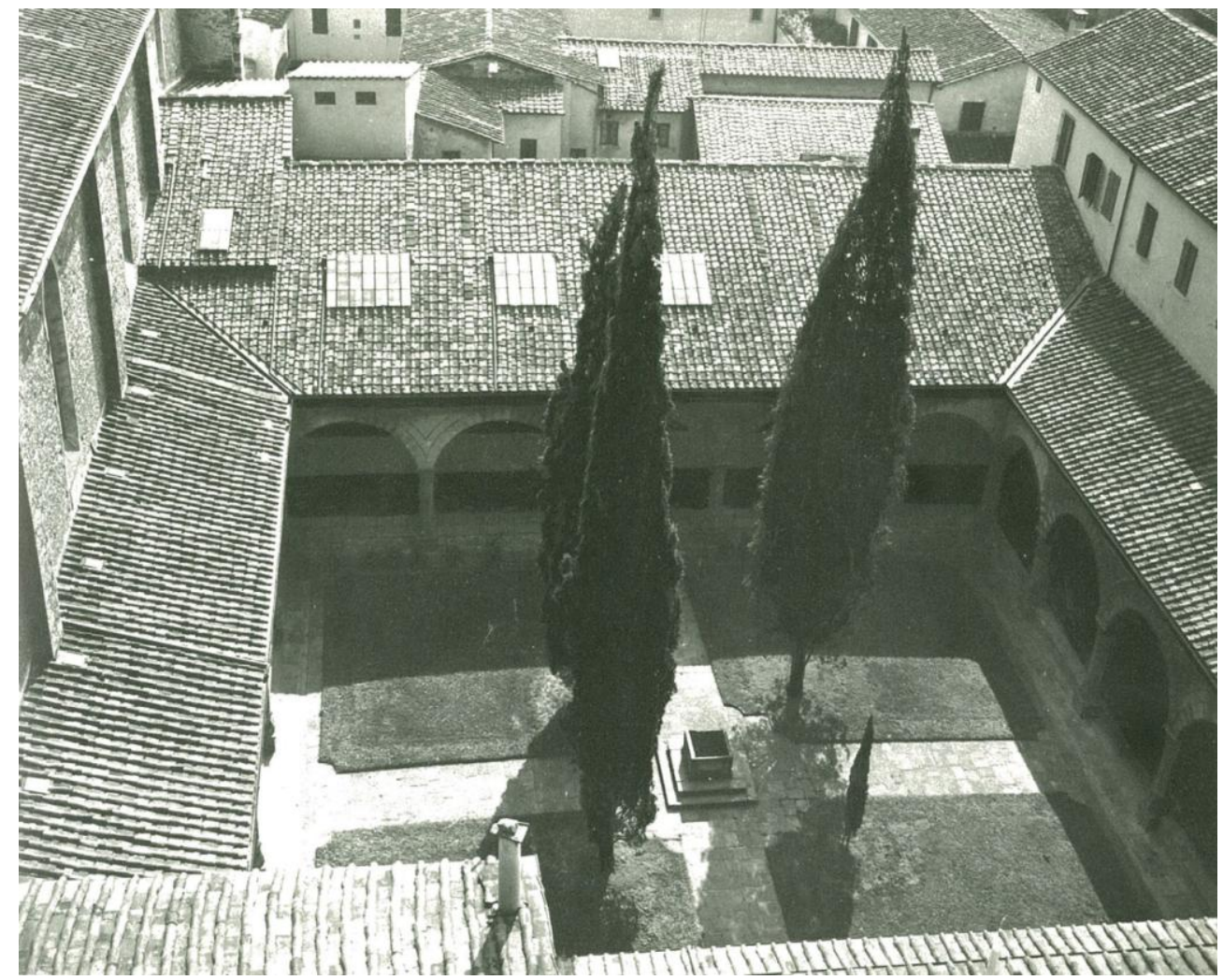

4. Claustro Verde en Santa Maria Novella

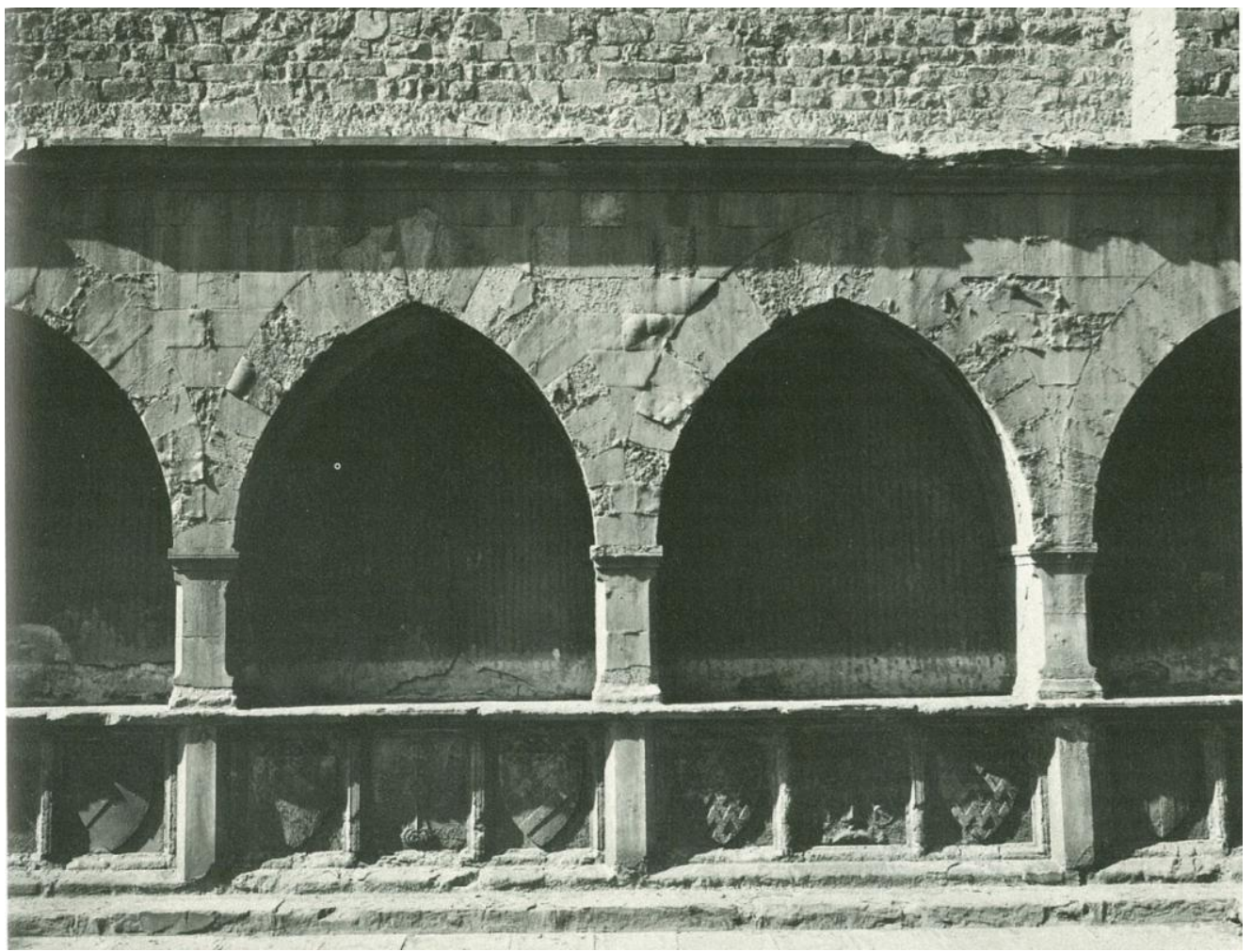

5. Alzado del claustro del cementerio en Santa Maria Novella 


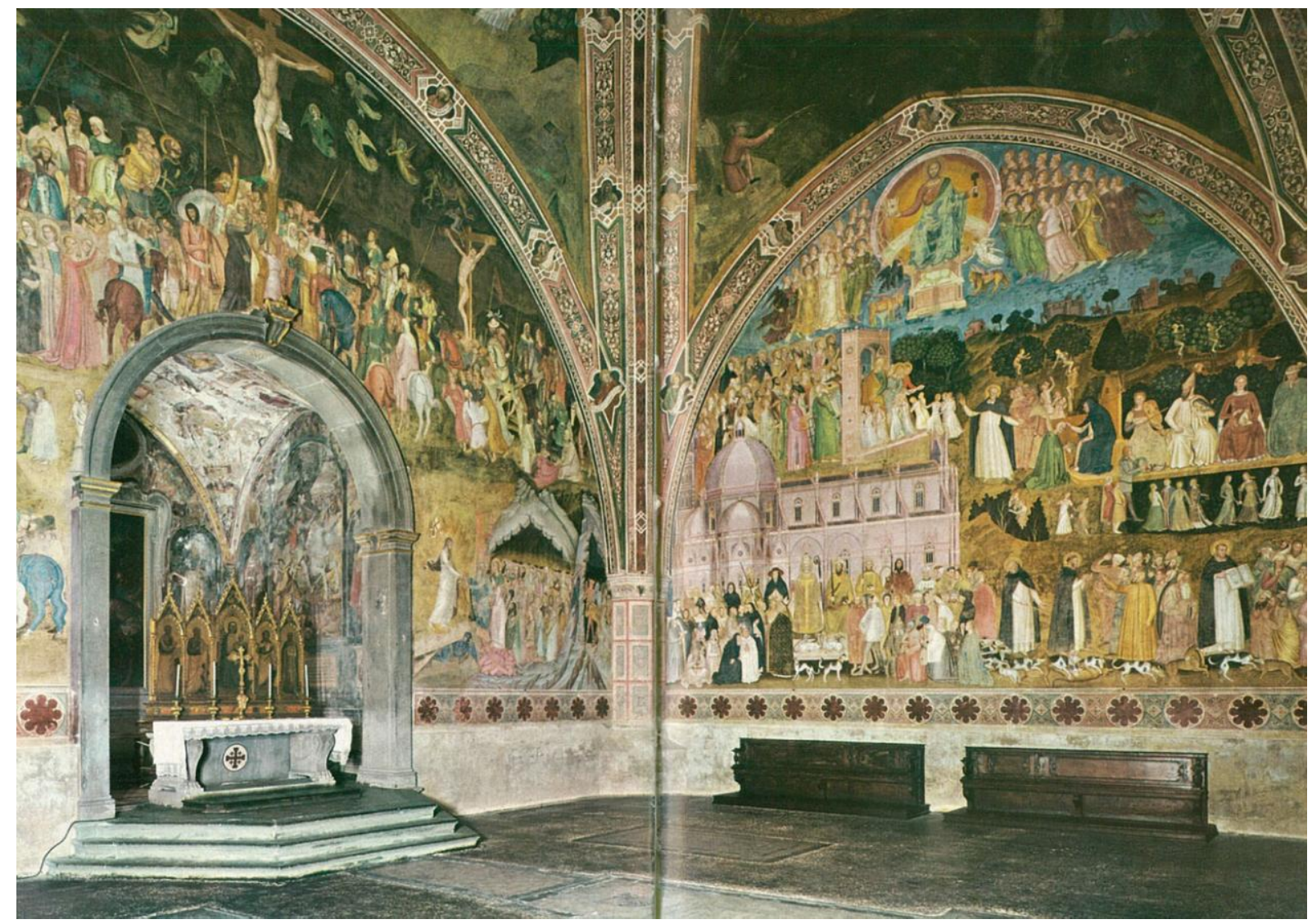

6. Interior de la capilla de los españoles en Santa Maria Novella

Le Corbusier en un papel que dibujó (FLC $4932^{19}$ ), poco después de comprar el libro de Ruskin, hace tres dibujos de la capilla de los españoles. En el primero, a lápiz y repasado a tinta, puede verse una perspectiva del espacio de los cuatro pilares, los arcos y la forma del techo; en el segundo, a lápiz, un alzado que, por la repetición, me atrevería a decir que es del claustro -verde-; el tercero, a tinta con inscripciones a lápiz, es el mas dañado, sólo tenemos un pedazo del dibujo, bastante detallado con algunas cotas y relaciones dimensionales. El dibujo, de mayor tamaño que los otros dos, se puede apreciar un grado de detalle poco habitual en los dibujos de la época de Le Corbusier y está hecho, además, desde el punto de vista del habitante o del espectador mostrando lo que vería este desde dentro de la capilla. El resto del papel está escrito ${ }^{20}$ haciendo referencias a lo que está dibujado.

\footnotetext{
${ }^{19}$ Fue Sekler quién primero miró este trozo de papel poco después de terminar su tesis doctoral y lo incluyó en su versión impresa con algunos comentarios: "Three diagrams and copious anotation concerns an análisis of the spatial arrangement of the Spanish Chapel at Santa Maria Novella in Florence. It is possible that Jeanneret's interest in this space was inspired by Ruskin's discussion of relative size and the effect of decorative tratment in comparing one bay in the Duomo with the space of the Spanish Chapel. p.624 Mary Patricia May Sekler, Early drawings of Charles-Edouard Jeanneret (Le Corbusier), ed. Garland Publishing, Inc. New York and London, 1977.

${ }^{20}$ Una posible transcripción de lo que dice se ofrece a continuación:

Le príncipe de la chapelle des Espagnoles / est celui de tout / ramener à (une) 1 seule / surface partant / depuis le pourtour / de la salle qui en / Somme ne será pas /tres grand, pour vous /recouvrir et vous envoûter comme par / enchantement en se / soient comme bout. Tout / l'art de constructeur / a été de remplir les / angles (,) de les dissimuler, / et l'oeil se promène / du sol jusqu'au bout / opposée, sans rencontrer / (une) 1 seule arête. Le príncipe / de l'éclairage par 2 fenêtres latérales, / placés très près du sol est (donnant( un demande / que la lumière du cloître qui cour / de l'autre côte du mur. Il m'a / paru que la
} 


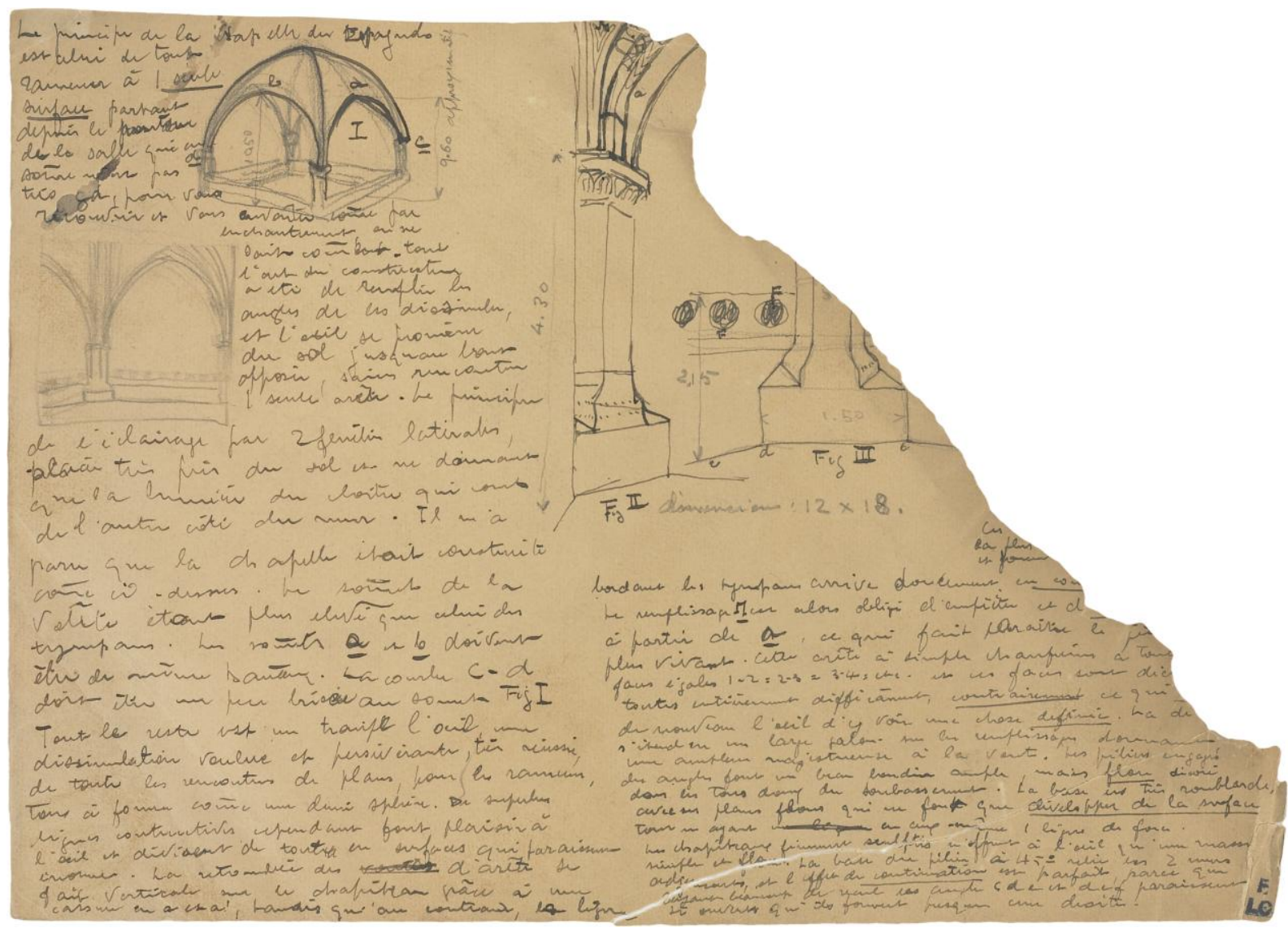

7. FLC 4932

El primer dibujo sirve para comprender el espacio, una especie de axonometría ${ }^{21}$, el tipo de dibujo que uno hace cuando llega a un lugar y quiere entender lo construido, un dibujo analítico. A continuación Le Corbusier traza el segundo dibujo -al que no hace referencia en el texto pero que está escrito antes que el texto, si no el texto no tendría este dibujo. Este dibujo es el que uno hace acordándose de lo que acaba de ver -el claustro- pero sin tenerlo delante, es un dibujo no hecho desde la percepción sino desde el análisis -un alzado ${ }^{22}$. El dibujo de

chapelle était construite / comme ci-dessus. Le sommet de la / voûtre étant plus élevé que celui des / tympans. Les sommets a et $\underline{b}$ doivent / être un même hauteur. La courbe c-d / doit être un peu brisé au sommet. Fig I. / Tout le reste est un trompe l'oeil une / dissimulation voulue et presévérante, très réussi, / de toutes les rencontres de plans, pour les ramener, / touts à forme comme une demi sphère. De superbes / lignes constructives ce pendant Font plaisir à l'oeil et devissent de tout en surfaces qui paraissent / énormes. La retombée d'arête se / fait verticale sur le chapiteau grâce à une /cassure en a est a, tandis qu'au contraire, le ligne // bordant les tympans arrivé doucement en co(...) / Le remplissage II car alors oblige d'empiéter et $\mathrm{d}(\ldots)$ / à partir de a , ce qui fait paraïtre le $(\ldots)$ / plus vivant. Cette arête à simples chapiteau a tout $(\ldots) /$ faces égales $1-2=2$ 3=3-4 etc. et ses faces sont $\operatorname{dic}(\ldots) /$ toutes entièrement diffus comme contrairement ce qui ... / de nouveaux l'oeil d'y voir une chose définis. La de... / s'étant en un large salón sur les remplissages donnant " une ampleur majestueuse à la voûtre. Les piliers engages / dans angles sont en bras ample mais flanc ivisée / dans les tors du soubassement . La base est très roublarde, / curves ses plans pour qui ne fornt que développer de la surface / tout en ayant en ceux mêmes (une) 1 ligne de forcé / Les chapiteaux firmament sculptes n'offerent à l'oeil qui en mass.. semples et fleurs. La base du pilier à $45^{\circ}$ reliés les 2 mur $/$ adjacentes et l'effet de continuation sont pafraits, parce que / ayant beaucoup de real les courbes $\underline{\mathrm{c}}$ et $\underline{\mathrm{d}}$ est paressent / les ouverts qui les formant persque un cloître.

${ }^{21} \mathrm{La}$ axonometria es el tipo de dibujo que usa Choisy para explicar muchos edificios. Es muy posible que sea el modo en que un discípulo de l'Epplatenier plantea el croquis para entender el espacio. Choisy, Auguste, Historie de l'architecture, 2.vol. Édouard Rouveyre, París 1899.

${ }^{22}$ De hecho al trazar la forma del arco Le Corbusier se equivoca y traza el arco que tiene delante o el que recuerda del claustro del cementerio de la propia Santa María Novella que seguro había visitado unos instantes antes. 
recuerdo aquí actúa como contrapunto, si el primer dibujo es para entender algo que "nos recubrirá y nos cautivará como por arte de magia" el primero es para entender cómo ese mecanismo se desarrolla. Cómo viniendo de un lugar tan falto de espacialidad desde el punto de vista de Le Corbusier, un lugar que se deja cortar por la sombra, que desliga los brazos del claustro dependiendo del momento del sol, entramos en otro que nos cautiva. El primer dibujo sirve para tratar de entender lo que se está viendo (así lo describe en el texto) el segundo para reflexionar de dónde se viene y cómo se ha producido el efecto cautivador. El primero sin el segundo carece de sentido. Es la comprensión de cómo Le Corbusier ha aprendido a mirar leyendo a Ruskin. Ruskin dice que la magnitud la capilla tiene que ver con que uno estando en el claustro verde no espera tal despliegue y Le Corbusier lo dibuja.

Le Corbusier se centra en el texto de FLC 4932, sobre todo, en cómo es la capilla porque el efecto inesperado que "cautiva como por arte de magia" lo ha dibujado. El contraste entre cómo entender, de forma plana, los arcos del claustro choca frontalmente con esos arcos que se entrecruzan para formar el espacio embelesador de la capilla.

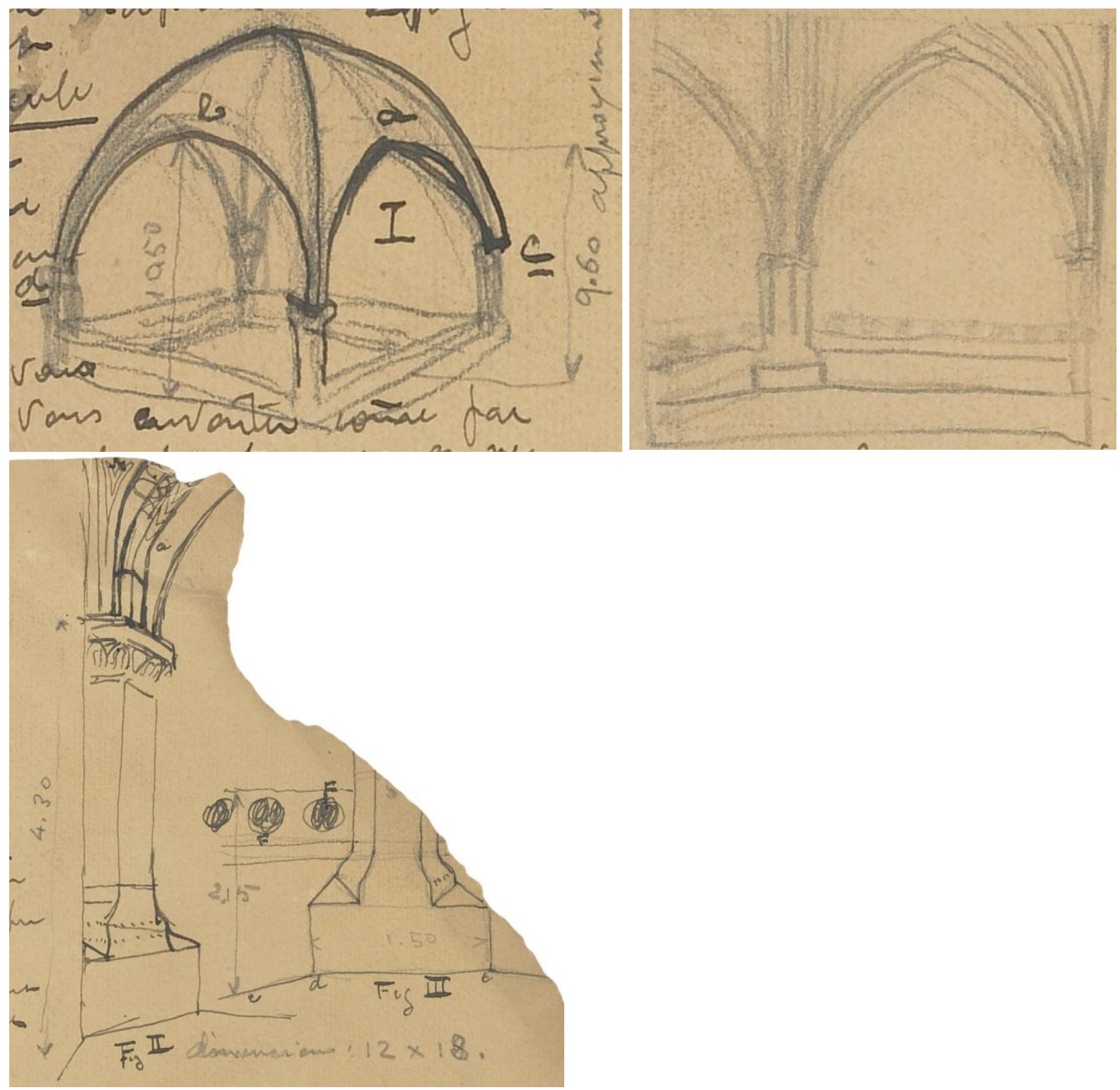

7, 8, 9.- Detalles de FLC 4932 
A la sucesión de esos contrastes, de esos choques, sin los que no aparece el espacio que "cautiva como por arte de magia”, es a lo que Le Corbusier llamará, más adelante, promenade.

Si en el choque radica el origen de la idea de promenade, la arquitectura de Le Corbusier no será sino una sucesión de choques para enseñarnos a mirar lo que tenemos alrededor. De este modo la arquitectura de Le Corbusier no será un paseo para gente amable sino mas bien un paseo lleno de sobresaltos y cosas inesperadas.

\section{Procedencia de las Imágenes:}

Figura 1.- Del libro: Le Corbusier. Précisions sur un état présent de l'architecture et de l'urbanisme, ed. Vincent, Fréal, Paris 1960

Figura 2.- Planta de Santa María Novella, redibujo.

Figura 3/4/5.- Las imagenes son del libro : Busignani, Alberto La chiese di Firenze. (v2) Quartiere di Santa Maria Novella., Sansoni, Firenze, 1979.

Figura 6.- La imágen es de la Guida di Santa María Novella.

Figura 7.- Fondation Le Corbusier.

\section{Bibliografía:}

Benton, Tim, "Le Corbusier y la promenade architecturale", En: Arquitectura COAM, Madrid, 1987, n.264-265

Brooks, H. Allen Le Corbusier's formative years. Charles-Edouard Jeanneret at La Chaux-de-Fonds. The university of Chicago Press, Chicago 1996

Cohen, Jean-Louis, Le Corbusier: An Atlas of Modern Landscapes, Museum of Modern Art, New York 2013

Coromina, Beatriz, Privacy and Publicity. Modern Architecture as Mass Media, The MIT press, 1994.

Daza, Ricardo, Tras el viaje de Oriente, Fundacion Arquia, Barcelona 2015

Etlin, Richard A., Frank Lloyd Wright and Le Corbusier. The romantic legacy, Manchester University Press, Manchester, 1994

Glaseri, Giuliano, Le Corbusier viaggio in oriente, Marsilio Editori, Foundation Le Corbusier, Venezia 1984

Le Corbusier et Pierre Jeanneret Oeuvre Complète 1929-1934, Grisberger \& Cie, Zurich, 1934

Le Corbusier. Précisions sur un état présent de l'architecture et de l'urbanisme, ed. Vincent, Fréal, Paris 1960

MacArthur, John, The Picturesque, Architecture, Disgust and other Irregularities. Routledge (Taylor and Francis group) London, 2007

Martínez de Guereñu, Laura, "Montage: Le Corbusier y Eisenstein" en Massilia. Annuaire d'Études Corbuseennes. 2008. Encuentro en Granada. Associació d'idees. Centre d'Investigacions Estètiques. Barcelona, 2009, pp.170-185

Moholy-Nagy, László, Vision in Motion, Theobald, Chicago, 1947

Quetglas, Josep, Les Heures Claires, Massilia, Sant Cugat del Vallès, 2008

Ruskin, John Mornings in Florence, The Mersion company, New York, 1897.

Samuel, Flora, Le Corbusier and the arhcitectural promenade, Brikhäuser, Zurich, 2010 